\title{
Erratum zu: Psychotherapie mit chronisch schmerzkranken Menschen
}

\section{Erratum zu:}

U. Frede, Psychotherapie mit chronisch schmerzkranken

Menschen, essentials, https://doi.org/10.1007/978-3-658-35053-6

Die Originalversion des Buches wurde revidiert. Die unnötigen Überschriften „Fragen“ zu didaktischen Boxen wurden entfernt.

Die aktualisierten Versionen der Kapitel sind verfügbar unter

https://doi.org/10.1007/978-3-658-35053-6_2

https://doi.org/10.1007/978-3-658-35053-6_3

https://doi.org/10.1007/978-3-658-35053-6_4

https://doi.org/10.1007/978-3-658-35053-6_5

(C) Der/die Autor(en), exklusiv lizenziert durch Springer Fachmedien 